\title{
A "modernização" no pensamento de Celso Furtado: desafio à construção da nação
}

\author{
The "modernization" in Celso Furtado's thought: challenge to nation building
}

\author{
Wilson Vieira \\ Professor adjunto do Instituto de Economia da \\ Universidade Federal do Rio de Janeiro (IE-UFRJ). \\ Pesquisador do Laboratório de Estudos Marxistas José \\ Ricardo Tauile (LEMA) do IE-UFRJ, Rio de Janeiro, RJ, \\ Brasil \\ vieiraeco@gmail.com; wilson.vieira@ie.ufrj.br
}

Resumo: O objetivo deste trabalho é analisar a reflexão de Celso Furtado sobre a "modernização", visto por ele como fator de continuidade do subdesenvolvimento brasileiro. A hipótese de trabalho é a de que tal reflexão leva Furtado a repensar mais profundamente tanto o seu diagnóstico do subdesenvolvimento quanto as propostas de sua superação e de construção da nação brasileira, entendida por ele como processo de unificação do espaço econômico nacional, através da valorização do mercado interno via políticas conduzidas pelo Estado, as quais garantiriam o vínculo de solidariedade entre as regiões brasileiras, num contexto político semelhante ao da socialdemocracia europeia. Para levar a cabo tal propósito, pretende-se utilizar como caminho metodológico o instrumental da sociologia do conhecimento de Karl Mannheim, além da teoria da linguagem política de John Pocock, para que possamos compreender o contexto e a linguagem do debate no qual Furtado se insere. Desse modo, busca-se aprofundar a amplitude teórica do pensamento furtadiano, privilegiando-se o aspecto interdisciplinar de sua análise sobre o Brasil.

Palavras-chave: "Modernização"; Pensamento de Celso Furtado; Desenvolvimento econômico; Nação.

Abstract: The objective of this article is to analyze the Celso Furtado's reflection about the "modernization", seen by him as a factor of Brazilian underdevelopment. The hypothesis is that this reflection leads Furtado to rethink more deeply the diagnosis of underdevelopment and the proposals for overcoming and construction of the Brazilian nation, understood by him as the process of the unification of the national economic space, through the enhancement the internal market via policies pursued by the state, which would ensure the bond of solidarity between Brazilian regions, in a political context similar to that of European social democracy. To carry out this purpose, we intend to use as a methodological way the Karl Mannheim's sociology of knowledge and the John Pocock's theory of political language, to understand the context and the language of debate in which Furtado takes part. Thus, we seek to deepen the theoretical breadth of Furtadian thought, privileging the interdisciplinary aspect of his analysis about Brazil.

Keywords: "Modernization"; Celso Furtado's thought; Economic development; Nation. 


\section{Introdução: breves considerações metodológicas}

O objetivo deste trabalho é analisar a reflexão de Celso Furtado sobre a "modernização", vista por ele como fator de continuidade do subdesenvolvimento brasileiro, tendo a hipótese de trabalho de que tal reflexão leva Furtado a repensar mais profundamente tanto o seu diagnóstico do subdesenvolvimento quanto as propostas de sua superação e de construção da nação brasileira, entendida por ele como processo de unificação do espaço econômico nacional, através da valorização do mercado interno via políticas conduzidas pelo Estado, as quais garantiriam o vínculo de solidariedade entre as regiões brasileiras, num contexto político semelhante ao da socialdemocracia europeia.

Portanto, a fim de atingirmos o fim para o qual é proposto este trabalho, é necessária uma breve exposição da metodologia de análise adotada, a qual se utiliza da sociologia do conhecimento de Karl Mannheim e da teoria da linguagem política de John Pocock, para que possamos compreender o contexto e a linguagem utilizados no debate ao qual Furtado se insere.

A sociologia do conhecimento de Karl Mannheim $(1972,1974)^{1}$, exposta primeiramente no livro Ideologia e Utopia ${ }^{2}$ e posteriormente no livro Sociologia da Cultura $^{3}$, possui as seguintes características:

I) Ela não parte do indivíduo isolado. Segundo Mannheim (1972, p. 31):

\begin{abstract}
Ao contrário, a Sociologia do Conhecimento busca compreender o pensamento no contexto concreto de uma situação histórico-social, de onde só muito gradativamente emerge o pensamento individualmente diferenciado. Assim, quem pensa não são os homens em geral, nem tampouco indivíduos isolados, mas os homens em certos grupos que tenham desenvolvido um estilo de pensamento particular em uma interminável série de respostas a certas situações típicas de sua posição comum.
\end{abstract}

II) Ela não separa os modos de pensamento concretamente existentes do contexto da ação coletiva, pois é através dela, num sentido

\footnotetext{
${ }^{1}$ Sociólogo alemão de origem húngara que teve grande influência na elaboração teórica de Furtado e também na sua ação através da ideia de planejamento democrático. Para mais detalhes, ver Furtado (FURTADO, 1997).

2 A primeira edição original em alemão foi publicada em 1929. Utilizamos a edição brasileira de 1972, publicada pela Zahar Editores.

3 A primeira edição original em inglês foi publicada postumamente em 1956 por Ernest Mannheim (seu sobrinho) sobre texto escrito em 1932. Utilizamos a edição brasileira de 1974, publicada pela Perspectiva e pela Editora da USP.
}

intelectual, que se descobre inicialmente o mundo. Mannheim (1972, p. 31-32) justifica tal afirmação da seguinte maneira:

\begin{abstract}
Homens vivendo em grupos não apenas coexistem fisicamente enquanto individuos distintos. Não se confrontam os objetos do mundo a partir de niveis abstratos de uma mente contemplativa em si, nem tampouco o fazem exclusivamente enquanto seres solitários. Pelo contrário, agem com ou contra os outros, em grupos diversamente organizados, e, enquanto agem, pensam com ou contra os outros. Estas pessoas, reunidas em grupos, ou bem se empenham, de acordo com o caráter e a posição dos grupos a que pertencem, em transformar o mundo da natureza e da sociedade a sua volta, ou, então, tentam mantê-lo em uma dada situação. A direção dessa vontade da atividade coletiva de transformar ou manter é que produz o fio orientador para a emergência de seus problemas, seus conceitos e suas formas de pensamento. De acordo com o contexto particular da atividade coletiva de que participam, os homens tendem sempre a ver diferentemente o mundo que os circunda.
\end{abstract}

E esses grupos sociais, cuja tarefa específica consiste em dotar a sociedade em que estão inseridos de uma interpretação, são denominados por Mannheim de intelligentsia.

Portanto, a utilização da sociologia do conhecimento de Karl Mannheim pode ser justificada das seguintes maneiras:

I) É o instrumental de análise adotado por Furtado, fato que nos permite compreender melhor a elaboração de suas reflexões.

II) Esse instrumental também nos permite compreender o debate sobre a relação nação e o binômio desenvolvimento-subdesenvolvimento, observando o contexto no qual ele está inserido: transformações radicais no capitalismo mundial, ascensão de ditaduras na América Latina, revisão da teoria cepalina do desenvolvimento, surgimento da teoria da dependência (tanto na vertente marxista quanto na vertente do desenvolvimento dependente e associado), e, mais especificamente no Brasil, a crise do período 1962-1967, a implantação do Plano de Ação Econômica Governamental (PAEG) entre 1964 e 1967, o "milagre" econômico brasileiro (1968-1973) e o II Plano Nacional de Desenvolvimento (II PND), entre 1974 e 1980. 
Como forma de complementar o instrumental da sociologia do conhecimento, utilizamos também a teoria da linguagem política de John Pocock (2003), exposta no livro Linguagens do Ideário Político, a qual afirma que determinados pensadores podem inovar na reflexão sobre um determinado tema ao lançarem uma nova linguagem, um novo vocabulário, um novo léxico, ou, na expressão do autor, uma nova langue que modificará a parole, ou seja, a própria maneira de se expressar e debater sobre determinado tema.

Portanto, a adoção da teoria da linguagem política de John Pocock se justifica pelo fato permitir que observemos a forma pela qual a reflexão sobre o binômio desenvolvimento-subdesenvolvimento feita por Furtado contribui para trazer uma nova linguagem, uma nova maneira de refletir sobre esse tema.

A partir das justificativas feitas acima, dividimos nosso trabalho da maneira que segue abaixo.

Apresentamos inicialmente e de maneira breve a conjuntura econômica, social e política entre 1964 e 1980, período de transformações na reflexão de Furtado. A partir daí, apresentamos de maneira breve as suas reflexões nas décadas de 1950 e 1960 e a sua teoria da "modernização", feita na década de 1970. Por fim, tecemos considerações finais, expondo os desdobramentos dessas reflexões.

\section{A conjuntura econômica, social e política entre 1964 e 1980: breves considerações ${ }^{4}$}

O período compreendido entre 1964 e 1980 é marcado por grandes transformações no Brasil e no mundo.

Entre 1930 e 1964, observamos o desenvolvimento da Industrialização por Substituição de Importações (ISI), que pode ser subdividida, segundo Mello (1982), em industrialização restringida (1930-1956), caracterizada pela predominância do Departamento III da economia (bens de consumo não duráveis) e em industrialização pesada (1956-1980), caracterizada pela implantação e desenvolvimento do Departamento II (bens de consumo duráveis) e do Departamento I (bens de capital).

No Brasil, frente aos reflexos da instabilidade econômica e política devido ao quadro de estagnação e inflação desde 1962 (como herança negativa do Plano de Metas de Juscelino Kubitschek, marco inicial da industrialização pesada, pois conseguiu implantar o Departamento II) e ao conturbado mandato de João Goulart, o qual teve um período parlamentarista (como solução à sucessão de Jânio Quadros, que renunciou

\footnotetext{
${ }^{4}$ Os parágrafos que seguem se baseiam largamente em Giambiagi et al. (2011), salvo indicações em contrário e citações específicas.
}

ao mandato apenas oito meses após tê-lo assumido em 1961) seguido de um período presidencialista com radicalizações à esquerda e à direita e tentativa de recuperação da economia através do Plano Trienal, elaborado por Celso Furtado, mas que mal saiu do papel. Tais instabilidades levaram à consumação de um golpe civil-militar em 1964, ou seja, um golpe de Estado liderado por forças da direita e pelos militares e que contou com o apoio decisivo dos EUA, dado o contexto de guerra fria com a então URSS. Esse golpe foi o primeiro de uma série dos que ocorreram na América Latina a partir de então e que instauraram ditaduras.

No caso brasileiro em particular, a ditadura militar perdurou por quase 21 anos (até 1985) e incialmente, no período 1964-1967, implementa o Plano de Ação Econômica Governamental (PAEG), que se propôs a combater o quadro de estagnação econômica e inflação (estagflação) através de duas frentes:

I) Conjuntural: aplicação de medidas de política econômica de caráter ortodoxo (inclusive arrocho salarial), variando somente na intensidade, ou seja, de tipo stop-and-go, a fim de promover a retomada do crescimento econômico com o combate à inflação, além da criação da correção monetária.

II) Estrutural: reforma profunda do sistema econômico nacional através das seguintes medidas:

A) Reforma do sistema financeiro nacional com a criação do Banco Central do Brasil (BACEN), do Conselho Monetário Nacional (CMN) e da Comissão de Valores Mobiliários (CVM);

B) Fim da estabilidade no emprego do setor privado após dez anos de permanência na mesma empresa e criação do Fundo de Garantia por Tempo de Serviço (FGTS), do Programa de Integração Social (PIS) e do Programa de Formação do Patrimônio do Servidor Público (PASEP);

C) Criação do Sistema Financeiro da Habitação (SFH) e do Banco Nacional da Habitação (BNH);

D) Reforma tributária, criando a estrutura tributária cuja maior parte ainda vigora.

O resultado de tais medidas é percebido na queda das taxas de inflação e na mudança dos rumos da política econômica a partir de 1967 , quando Delfim 
Netto assume o Ministério da Fazenda e defende a retomada de um ritmo mais vigoroso de crescimento econômico através do argumento de que a manutenção de políticas econômicas de caráter recessivo poderiam fazer a inflação voltar a crescer, dada a alta capacidade ociosa da economia e os altos custos em mantê-la, ou seja, a inflação que poderia voltar a crescer seria caracterizada como de custos.

Portanto, tendo em vista tal diagnóstico, inicia-se um período de vigoroso crescimento econômico (fruto do Plano Estratégico de Desenvolvimento) que ficou conhecido como "milagre" econômico brasileiro e que durou até 1973 sem ter completado, contudo, a implantação do Departamento I, além de ter se caracterizado como concentrador de renda e com arrocho salarial.

Porém, devido ao primeiro choque do petróleo em 1973 e ao esgotamento da capacidade produtiva, o período do "milagre" chega ao fim e em 1974 o início do governo Geisel se vê diante de duas opções: implantar medidas de contenção da atividade econômica ou avançar na ISI, a fim de terminar a implantação do Departamento I da economia, ou seja, internalizando-o, a fim de superar a dependência externa dos bens de capital.

O governo Geisel optou pela segunda alternativa, implantando o II Plano Nacional de Desenvolvimento (II PND), dentro do projeto "Brasil potência", cujo objetivo era tornar o país uma potência, pelo menos em nível regional, além de tomar parte do movimento dos países não alinhados, procurando se distanciar um pouco da esfera de influência dos EUA.

Sobre o II PND, mais especificamente, observamos que os investimentos foram predominantemente das empresas estatais, com pouca ou nenhuma participação das empresas transnacionais, dada a conjuntura internacional adversa, e pouca participação das empresas privadas nacionais, que se opuseram a tal plano, por considerá-lo extremamente intervencionista. Além desses fatos, o financiamento se deu através de endividamento externo.

Em 1979, o início do governo de João Figueiredo, diante do segundo choque do petróleo, também se vê diante de duas alternativas que se colocaram em choque nas figuras de Mário Henrique Simonsen (Ministro do Planejamento) que defendia medidas restritivas da atividade econômica para enfrentar a crise e segurar a inflação crescente e, Delfim Netto (Ministro da Agricultura) que defendia a continuação dos investimentos do II PND e uma reedição do "milagre" econômico. A segunda alternativa foi a vencedora, com Simonsen saindo do governo e Delfim Netto assumindo o Ministério do Planejamento, num governo que seria marcado, em termos econômicos:
I) Pela tentativa de reedição do "milagre" econômico em 1979 e 1980

II) Pela crise da dívida externa a partir de 1979 (devido ao aumento dos juros do dólar) a qual levaria o governo a uma renegociação inicialmente com os credores e posteriormente com o FMI (após a moratória mexicana de 1982) e a um ajuste recessivo entre 1981 e 1983.

III) Pela saída da recessão em 1984 devido à recuperação da economia americana e à maturação dos investimentos do II PND.

IV) Pela inflação elevada e persistente, de caráter inercial.

\section{Antecedentes: a reflexão de Celso Furtado nas décadas de 1950 e 1960}

A reflexão de Celso Furtado nas décadas de 1950 e 1960 pode ser subdividida em três períodos: o da atuação na Comissão Econômica para a América Latina e o Caribe - CEPAL (entre 1949 e 1958), o da atuação na Superintendência para o Desenvolvimento do Nordeste - SUDENE (entre 1959 e 1964, incluindo o período em que atuou no Ministério do Planejamento) e o do início do exílio (entre 1964 e 1970).

No período da CEPAL, observamos um desdobramento e aprofundamento das reflexões iniciadas na sua tese de doutorado elaborada na Universidade de Paris, A Economia Colonial no Brasil nos Séculos XVI e XVII (FURTADO, 2001), como podemos observar no artigo Características Gerais da Economia Brasileira (FURTADO, 1950), e nos livros A Economia Brasileira (FURTADO, 1954a) e Uma Economia Dependente (FURTADO, 1956a), constituído de alguns capítulos do livro A Economia Brasileira (FURTADO, 1954a). Além do terreno da história econômica especificamente, Furtado também elaborou vários artigos nos quais defendia a ideia de planejamento da CEPAL, dentro do debate que se travava no Brasil entre os desenvolvimentistas e os liberais ${ }^{5}$. Observamos uma reflexão localizada mais no terreno da análise econômica stricto sensu, apesar da sua interdisciplinaridade, além da crença na industrialização planejada sob a liderança do Estado para a superação do subdesenvolvimento, tal como Raúl Prebisch (1949), Secretário Executivo da CEPAL nesse período, defende no Manifesto Latino-Americano.

Em 1958, após sua saída da CEPAL, dedicou-se à pesquisa na Universidade de Cambridge (Reino Unido)

\footnotetext{
5 Para mais detalhes ver Bielschowsky (2000) e Furtado (1953, 1954b, 1956b, 1958).
} 
que resultou no livro Formação Econômica do Brasil (FURTADO, 2007), considerada por muitos dos seus estudiosos como a sua maior obra. É a partir dessas reflexões que Furtado voltaria sua atenção até 1964 no problema das disparidades regionais no Brasil através da luta para a criação da SUDENE, a qual se concretiza em 1960, tendo sido ele o seu primeiro superintendente. Nesse período observamos uma reflexão de caráter mais interdisciplinar, em que há um otimismo com o processo de industrialização no Brasil, apesar dele observar suas primeiras dificuldades na década de 1960, além de uma elaboração, que podemos dizer, é um pouco diferente daquela de Prebisch, sobre a relação desenvolvimentosubdesenvolvimento. Essas reflexões estão presentes nas obras Desenvolvimento e Subdesenvolvimento (FURTADO, 1961), A Pré-Revolução Brasileira (FURTADO, 1962) e Dialética do Desenvolvimento (FURTADO, 1964). Nesse período, Furtado assume por alguns meses o então recém-criado Ministério do Planejamento (a convite do Presidente João Goulart), elabora o Plano Trienal para promover o combate à inflação e a retomada do desenvolvimento, mas que nem conseguiu ser concretizado na prática devido à situação de forte instabilidade política (como observamos no item anterior), fato que leva Furtado de volta ao comando da SUDENE até o golpe civil-militar de 1964.

Podemos afirmar que as reflexões de Furtado estão inseridas no grande debate sobre nação e desenvolvimento econômico ocorrido nesse período. Observamos que ele se posiciona de maneira contrária à teoria do desenvolvimento econômico elaborada no centro $^{6}$, na qual via o subdesenvolvimento como uma etapa anterior ao desenvolvimento, bastando, portanto, para superá-lo, seguir o caminho feito pelos países desenvolvidos. Na qualidade de membro da CEPAL na década de 1950, ele compartilha da posição de Raúl Prebisch, que observa o subdesenvolvimento como o outro lado do processo de desenvolvimento e não como uma etapa anterior a este e cuja superação passaria pela industrialização planejada pelo Estado.

Dentro do debate sobre nação mais especificamente, Furtado está inserido, no debate mundial, naqueles que chamam a atenção para o processo peculiar de construção das nações do Terceiro Mundo, que, numa análise modernista, procura seguir os valores da nação a partir da Revolução Francesa, mas através de um caminho próprio, com ampla participação do Estado no planejamento para industrialização, num modelo socialdemocrata ${ }^{7}$. Essa posição vai de encontro àquela

\footnotetext{
${ }^{6}$ Podemos encontrar exemplos em Rostow (1964) e Millikan \& Blackmer (1963).

7 Observamos essa posição em Myrdal (1972), Nurkse (1957), Matossian (2000), Geertz (2000) e Bendix (1996).
}

que via a construção da nação no Terceiro Mundo através de um mero transplante do processo vivido no Primeiro Mundo sem levar em conta as especificidades da periferia ${ }^{8}$.

No Brasil em especial, Furtado toma parte no rico debate que ocorre sobre nação e desenvolvimento, tomando parte entre os desenvolvimentistas do setor público nacionalista. Destacamos os seguintes nomes nesse debate: Caio Prado Júnior, Ignácio Rangel, Partido Comunista Brasileiro (PCB), Roberto Simonsen, Eugênio Gudin, Octávio Gouvêa de Bulhões, Roberto Campos, Instituto Superior de Estudos Brasileiros (ISEB) ${ }^{9}$.

Nesse período, é clara a identificação da construção da nação com o projeto de desenvolvimento econômico, entendida por Furtado como processo de unificação do espaço econômico nacional, através da valorização do mercado interno via políticas conduzidas pelo Estado, as quais garantiriam o vínculo de solidariedade entre as regiões brasileiras, num contexto político semelhante ao da socialdemocracia europeia.

Logo após o golpe civil-militar de 1964, Furtado, cassado de seus direitos políticos no Ato Institucional $\mathrm{n}^{\mathrm{o}} 1$, parte para o exílio, primeiramente no Chile, depois para os EUA e finalmente para a França (em 1965), onde assume cargo de professor na Universidade de Paris (Sorbonne). Nesse período, observando a situação de estagnação da economia brasileira (que se iniciara em 1962 e ainda perdurava naquele momento) e o poder hegemônico dos EUA sobre a América Latina, ele elabora um diagnóstico e um prognóstico pessimista caso nada fosse feito para modificar tal situação, fato que o leva a propor alternativas, como observamos em Subdesenvolvimento e Estagnação na América Latina (FURTADO, 1966), Um Projeto para o Brasil (FURTADO, 1968a) e Brasil: da República Oligárquica ao Estado Militar (FURTADO, 1968b). Dentro dessa reflexão, observamos as seguintes inovações na sua análise, tais como:

I) O conceito de "efeito de demonstração", isto é, imitação, pelas classes pobres dos países periféricos, do padrão de consumo das suas classes médias, e destas, do padrão de consumo das classes médias dos países centrais.

II) A percepção de que a assimilação da tecnologia moderna continuaria acarretando efeitos negativos sobre a taxa de criação de novos empregos, além do aumento da concentração de renda.

\footnotetext{
${ }^{8}$ Essa posição pode ser vista em Kohn (1963).

${ }^{9}$ Para mais detalhes, ver Mantega (1984) e Bielschowsky (2000).
} 
III) Inclusão da análise sobre a transnacionalização do capital, mostrando a sua penetração na periferia, acompanhada de desequilíbrios estruturais de difícil correção (maiores disparidades de níveis de vida entre grupos de população e rápido aumento do desemprego aberto e disfarçado).

Esses novos pontos de análise se constituiriam na base da sua reflexão sobre a "modernização" a partir da década de 1970, como observamos no próximo item.

\section{A "modernização": inovação no pensamento de Celso Furtado na década de 1970}

A partir do golpe civil-militar de 1964, observamos na reflexão de Furtado uma ampliação cada vez maior de sua perspectiva teórica, adotando de maneira crescente o caminho da interdisciplinaridade. Isso se mostra presente no diagnóstico estagnacionista (como vimos no item anterior) e, de maneira mais radical, a partir de suas obras da década de 1970, conforme analisamos nos parágrafos seguintes.

$\mathrm{Na}$ verdade, as reflexões de Furtado após 1964 reforçam o que ele já havia percebido a partir de 1960, ou seja, de que a industrialização não conseguiu equacionar as questões sociais. Tal constatação leva o referido teórico, juntamente com Prebisch ${ }^{10}$, a fazerem suas autocríticas e proporem a inclusão da necessidade de políticas sociais e de distribuição de renda para sair do subdesenvolvimento e, assim, construir a nação.

Dentro dessa linha de crítica ao desenvolvimentismo cepalino, nesse período também observamos o surgimento da teoria da dependência nas suas duas vertentes, a saber:

I) Vertente marxista: composta por Ruy Mauro Marini, Theotonio dos Santos e Vânia Bambirra (principais membros) os quais criticam a tese da estagnação defendida por Furtado e veem uma nova fase do subdesenvolvimento, isto é, a da dependência. Segundo Santos (2000, p.134) ${ }^{11}$ :

Combati em 1964 todas as teses estancacionistas que viam na política de estabilização monetária de Roberto Campos a destruição da indústria brasileira. Ao contrário, afirmei que a política de estabilização deveria levar a uma nova fase de crescimento, baseada contudo num nível mais

\footnotetext{
${ }^{10}$ Para mais detalhes, ver Prebisch (1964).

${ }^{11}$ Para mais detalhes, ver Santos (2000).
}

alto de produtividade, concentração econômica, monopolização e estatização (...).

II) Vertente do desenvolvimento dependente e associado: composta por Fernando Henrique Cardoso e Enzo Faletto (principais membros), os quais também questionam as teses estagnacionistas do período, mas veem como saída para o subdesenvolvimento um desenvolvimento dependente e associado ${ }^{12}$.

Nesse contexto de reflexão, Furtado, ao observar que a economia brasileira não continuou estagnada, mas voltou a apresentar crescimento econômico no período 1968-1973, denominado de "milagre" econômico brasileiro, reavalia suas reflexões anteriores (coerente com a dinamicidade de seu diagnóstico do subdesenvolvimento) e inova na sua teoria ao elaborar o termo "modernização", mantido entre aspas porque não se trata de uma modernização que leve ao desenvolvimento econômico, mas sim que traz crescimento econômico, mas não supera a situação de subdesenvolvimento.

O termo "modernização" aparece pela primeira vez no livro Análise do "Modelo" Brasileiro $(\text { FURTADO, 1982) })^{13}$. A palavra modelo aparece entre aspas para denotar que não se trata de um modelo de desenvolvimento econômico, como se apregoava na época tanto no Brasil quanto no exterior, mas sim um caso de crescimento econômico conjugado com forte concentração de renda, fruto de reformas econômicas feitas pela ditadura militar no período 1964-67 através do Plano de Ação Econômica Governamental (PAEG), como vimos anteriormente. Segundo Furtado (1982), esse período demonstra claramente que somente a industrialização não traz automaticamente o desenvolvimento socioeconômico.

Para fundamentar sua análise sobre a "modernização", Furtado (1982) inicialmente chama a atenção sobre a história do subdesenvolvimento, fortemente ligada à da Revolução industrial, percebida nas formas que ela assumiu: i) transformação de técnicas produtivas, inicialmente nas manufaturas e nos meios de transporte; ii) modificação nos padrões de consumo. Essas transformações ocorridas em conjunto caracterizam os países desenvolvidos. Naqueles países em que essas transformações ocorreram somente nos padrões de consumo (mesmo que de uma minoria da população), observamos o fenômeno do subdesenvolvimento. Segundo Furtado (1982, p. 10-11): “A característica

\footnotetext{
${ }^{12}$ Para mais detalhes, ver Cardoso e Faletto (1984). A primeira edição foi em 1970 .

${ }^{13}$ A primeira edição é de 1972 . Utilizamos a de 1982.
} 
essencial das estruturas subdesenvolvidas estaria, assim, nessa desigual assimilação das duas formas básicas de progresso tecnológico. Uma vez estabelecida a discrepância, uma série de fatores tornou extremamente difícil sua eliminação subsequente".

Furtado (1982, p. 11-12) continua sua argumentação, complementando o afirmado acima:

\begin{abstract}
A história do subdesenvolvimento consiste, fundamentalmente, no desdobramento desse modelo de economia em que o progresso tecnológico serviu muito mais para modernizar os hábitos de consumo do que para transformar os processos produtivos. A partir do momento em que entrou em declínio o sistema tradicional de divisão internacional do trabalho - ou seja, quando a demanda internacional de produtos primários passou a crescer com relativa lentidão-ou, no caso de certas regiões, os recursos naturais de fácil utilização foram plenamente utilizados - os países subdesenvolvidos tiveram de tomar o caminho da industrialização. (...). Na fase de industrialização, a característica fundamental das estruturas subdesenvolvidas está em que o nível tecnológico correspondente aos padrões de consumo, isto é, ao nível de modernização, restringe a difusão do progresso tecnológico, isto é, sua generalização ao conjunto das atividades produtivas. (...). Na linguagem dos sociólogos latino-americanos, mais excludente é o desenvolvimento.
\end{abstract}

Portanto, na visão de Furtado (1982, p. 13,15), enquanto nos países desenvolvidos o fluxo de novos produtos e o complexo de inovações tecnológicas que o acompanham são essenciais para o funcionamento da economia capitalista, se observamos tal fato no âmbito mundial, percebemos que tais fatores preservam as relações de dominação e de dependência, explicitando o subdesenvolvimento, uma situação de dependência estrutural, que pode ser traduzida por um horizonte estreito de opções na formulação de objetivos próprios, além de reduzida capacidade de articulação das decisões econômicas tomadas em função desses objetivos ${ }^{14}$.

A partir da definição e da análise da "modernização" nos países subdesenvolvidos, Furtado mostra como se dá esse processo no caso específico brasileiro do "milagre" econômico, como observamos abaixo.

O "milagre" foi baseado em forte concentração da renda mediante compressão salarial, contudo, sem ser estática, mas sim dinâmica, ou seja, porque também contou com a ampliação do grupo social consumidor do mercado de bens de consumo duráveis (além da minoria proprietária de bens de capital, com inclusão da classe

\footnotetext{
${ }^{14}$ Aqui observamos uma aproximação com a vertente marxista da teoria da dependência quando Furtado utiliza as palavras dominação e dependencia, participando do processo de introdução de uma nova langue na parole, como Pocock (2003) afirma.
}

média) através do financiamento do consumo em suas várias formas (subsídios ao consumo e transferências de títulos de propriedade e de crédito). Tais medidas foram tomadas para evitar dificuldades da retomada do processo de industrialização (depressão predominante em importantes segmentos da atividade econômica) que certamente ocorreriam se a concentração de renda continuasse a ser estática.

Como forma de sistematização, é oportuno citar a seguinte passagem, na qual o autor antecipa pontos nos quais reflete com mais profundidade em $O$ Mito do Desenvolvimento Econômico (FURTADO, 1974), o qual analisamos sucintamente neste trabalho. Nas palavras de Furtado (1982, p. 77, grifo nosso):

\begin{abstract}
A economia industrial subdesenvolvida não constitui uma fase que tende a ser necessariamente superada em prazo maior ou menor. O funcionamento desse sistema requer a preservação de certas estruturas sociais, sem as quais não se daria o processo de reprodução de padrões de consumo, cujo transplante é condição sine qua non para que prossiga a industrialização tal qual esta se está realizando. Assim, desenvolvimento passa a ser definido em termos de aproximação de um paradigma que, por definição, é inalcançável, porquanto em transformação cada vez mais rápida. A experiência já demonstrou que, se se aumenta o esforço para andar mais rápido e reduzir a distância do alvo perseguido, a deformação estrutural se acentua, pois uma acumulação mais intensa em benefício de uma parte da população amplia o fosso que existe entre as condições de vida da minoria beneficiada e as da massa, fosso que é a essência mesma do subdesenvolvimento. Cabe inferir, portanto, que a melhoria efetiva das condições de vida da massa da população dos países do Terceiro Mundo, particularmente dos de grande dimensão demográfica, somente será alcançada por outros caminhos. A Índia nunca será uma Suécia de um bilhão de habitantes, nem o Brasil uma reprodução dos Estados Unidos ${ }^{15}$.
\end{abstract}

No livro O Mito do Desenvolvimento Econômico (FURTADO, 1974), Furtado busca aprofundar o significado da "modernização" para os países subdesenvolvidos. Podemos observar isso nos seguintes pontos:

I) A "modernização" está inserida no processo de industrialização da periferia, a qual não se orienta para formar um sistema econômico nacional, mas sim para completar o sistema

\footnotetext{
${ }^{15}$ Palavras em negrito: grifo nosso. Furtado (1982, p. 77-78) ainda acrescenta, como forma de nos chamar a atenção [também antecipando o que reflete com profundidade em $O$ Mito do Desenvolvimento Econômico (FURTADO, 1974)], o fato da tendência à elevação dos custos sociais do desenvolvimento nos países capitalistas avançados, tanto em termos de destruição do meio ambiente como no de geração de tensões psicossociais.
} 
econômico internacional. Essa industrialização é algo específico das economias subdesenvolvidas. Segundo Furtado (1974, p. 25):

[É] pelo lado da demanda de bens finais de consumo que esses países se inserem mais profundamente na civilização industrial. Esse dado é fundamental para compreender o sentido que neles tomará, em fase subsequente, o processo de industrialização.

II) A industrialização periférica conta, de maneira cada vez mais forte, com a presença das grandes empresas transnacionais. Segundo Furtado (1974, p. 26-27):

A rápida industrialização da periferia do mundo capitalista, sob a direção de empresas dos países cêntricos, que se observa a partir do segundo conflito mundial e se acelerou no último decênio, corresponde a uma terceira fase na evolução do capitalismo industrial. Essa fase se iniciou com um processo de integração das economias nacionais que formam o centro do sistema. (...). O movimento de capitais, dentro desse espaço em vias de unificação, alcançou volume considerável (...), o que permitiu que grandes empresas se implantassem em todos os subsistemas nacionais e também que as estruturas oligopólicas viessem a abranger o conjunto desses subsistemas. A formação, a partir da segunda metade dos anos 60, de um importante mercado internacional de capitais constitui o coroamento desse processo, pois permite às grandes empresas liberar-se de muitas das limitações criadas pelos sistemas monetários e financeiros nacionais.

III) A partir das modificações estruturais ocorridas no centro (transnacionalização das grandes empresas e financeirização crescente do capital), principalmente a partir da segunda metade da década de 1960, observamos as seguintes consequências: a) processo de unificação dos países centrais, o qual levou a uma intensificação do seu crescimento; b) ampliação considerável do fosso entre o centro e a periferia; c) as relações comerciais entre países centrais e periféricos (mais ainda do que entre os países do centro) se transformaram progressivamente em operações internas das grandes empresas.

IV) A “modernização" é uma manifestação de mimetismo cultural da periferia. Segundo Furtado (1974, p. 80, grifo nosso):
Para captar a natureza do subdesenvolvimento, a partir de suas origens históricas, é indispensável focalizar simultaneamente o processo da produção (realocação de recursos dando origem a um excedente adicional e forma de apropriação desse excedente) e o processo da circulação (utilização do excedente ligada à adoção de novos padrões de consumo copiados de países em que o nível de acumulação é muito mais alto), os quais, conjuntamente, engendram a dependência cultural que está na base do processo de reprodução das estruturas sociais correspondentes ${ }^{16}$.

V) A partir dos pontos listados acima, Furtado (1974, p. 81-82, grifo nosso), então, define a "modernização" da seguinte maneira:

Chamaremos de modernização a esse processo de adoção de padrões de consumo sofisticados (privados e públicos) sem o correspondente processo de acumulação de capital e progresso nos métodos produtivos. Quanto mais amplo o campo do processo de modernização (e isso inclui não somente as formas de consumo civis, mas também as militares) mais intensa tende a ser a pressão no sentido de ampliar o excedente, o que pode ser alcançado mediante expansão das exportações, ou por meio de aumento da "taxa de exploração", vale dizer, da proporção do excedente no produto líquido. (...). Dai que apareçam crescentes pressões, ao nível da balança de pagamentos, quando o país atinge o ponto de rendimento decrescente na agricultura tradicional de exportação elou enfrenta deterioração nos termos de intercâmbio. (...). A importância do processo de modernização, na modelação das economias subdesenvolvidas, só vem à luz plenamente em fase mais avançada quando os respectivos países embarcam no processo de industrialização; mais precisamente, quando se empenham em produzir para o mercado interno aquilo que vinham importando. (...). Ao impor a adoção de métodos produtivos com alta densidade de capital, a referida orientação cria as condições para que os salários reais se mantenham próximos ao nível de subsistência, ou seja, para que a taxa de exploração aumente com a produtividade do trabalho ${ }^{17}$.

\footnotetext{
${ }^{16}$ Palavras em negrito: grifo nosso. Aqui Furtado aprofunda ainda mais sua análise interdisciplinar ao introduzir a questão da dependência cultural, ponto que seria desenvolvido com mais detalhes em Criatividade e Dependência na Civilização Industrial (FURTADO, 1978).

${ }^{17}$ No trecho em negrito (grifo nosso), podemos notar, em princípio, certa semelhança com a tese da superexploração da força de trabalho na periferia (trabalhadores explorados pela burguesia nacional e pela burguesia do centro capitalista) tal como Marini (2000) teoriza. Para mais detalhes, ver Bichir (2012), Marini (2000) e Santos (2000).
} 
Em Prefácio a Nova Economia Política (FURTADO, 1976), observamos a retomada de pontos analisados nas obras que expomos acima, além do acréscimo dos seguintes:

I) A ideologia do progresso é um forte impulsionador da industrialização periférica.

II) Consequências da penetração do modo capitalista de produção no quadro da dependência externa: tensões na estrutura de dominação interna (fenômeno da insegurança social) e revoluções sociais (que podem ocorrer ocasionalmente). Segundo Furtado (1976, p. 60-61):

A fragilidade das estruturas de dominação das formações capitalistas dependentes vem sendo atestada pelas repetidas rupturas nos sistemas de poder, ocorridas no último meio século. Em alguns casos essas rupturas foram acompanhadas de transformações profundas nas estruturas sociais, em muitos outros limitam-se a provocar uma maior participação do Estado no controle de produção. Mas, a regra tem sido o crescimento relativo da forma autoritária de apropriação do excedente, que tende a fazer-se hegemônica. Parece fora de dúvidas, por conseguinte, que tais rupturas estão ligadas à forma irregular que assumiu a difusão do modo capitalista de produção, às desigualdades no nivel e na forma da acumulação e às relações de dependência decorrentes.

III) Ocorre um duplo processo de concentração de renda: em benefício dos países centrais e, dentro de cada país periférico, em benefício da minoria que reproduz o estilo de vida do centro $^{18}$.

IV) Furtado chama a atenção para pontos importantes a serem estudados, a fim de compreendermos melhor esse processo de "modernização": a) os grupos que controlam as principais atividades econômicas nos países latino-americanos; b) as relações dos Estados nacionais com as empresas transnacionais.

No livro Criatividade e Dependência na Civilização Industrial (FURTADO, 1978), que pode ser considerado seu livro mais interdisciplinar, destacamos os seguintes pontos de análise sobre a "modernização" e a dependência:

\footnotetext{
${ }^{18}$ Aqui essa análise também se assemelha àquela de Marini (2000) sobre a superexploração dos trabalhadores da periferia (e de maneira mais patente).
}

I) As estruturas sociais internas na periferia são importantes para a compreensão da industrialização dependente. Segundo Furtado (1978, p. 49):

[É] na evolução das estruturas sociais internas que se vê com clareza a especificidade da industrialização dependente. Sua estreita vinculação com o comércio exterior somente pode ser percebida em toda sua complexidade se se tem em conta que a ela corresponde um importante papel na reprodução dos setores sociais que tiveram acesso, ainda que por via indireta, aos valores materiais da civilização industrial. Esta a razão pela qual essa industrialização tem como eixo o fluxo de importações, sendo de menor relevância as suas vinculações com o sistema pré-existente de forças produtivas.

II) A “modernização" também significou ocidentalização, isto é, destruição de valores culturais em vários países da periferia sem haver uma substituição adequada.

III) Apesar do quadro negativo na periferia, Furtado (1978, p. 114-116) vê possibilidades de superação:

A luta contra a dependência passa, portanto, por um esforço para modificar a conformação global do sistema. Que se esteja atualmente discutindo essa questão-mais precisamente: que a conformação global do sistema haja sido questionada - é clara indicação de que a relação de forças se está modificando a favor dos paises dependentes. Certo: em grande parte dos paises periféricos, as relações externas de dependência estão introjetadas nas estruturas de dominação social. Mas, conforme já observamos, isso não impede a emergência de estruturas de poder tecnoburocrático capazes de explorar a nova situação que se está formando. (...). Dentre os recursos de poder em que se assenta a chamada ordem econômica internacional têm particular relevância: a) o controle da tecnologia, b) o controle das finanças, c) o controle dos mercados, $d$ ) o controle do acesso às fontes de recursos não renováveis, e e) o controle do acesso à mão de obra barata. Esses recursos, reunidos em quantidades ponderáveis elou combinados em doses diversas, originam posições de força, que ocupam os Estados ou os grandes grupos econômicos na luta pela apropriação do excedente gerado pela economia internacional. Essas posições de força são de peso diferente e em seu relacionamento tendem a ordenar-se, produzindo uma estrutura. A luta contra a dependência não é outra coisa senão um esforço de países periféricos para modificar essa estrutura. Coligações de paises permitem ocasionalmente obter a massa crítica requerida para o controle de 
um recurso, ou articular combinações de recursos de alta eficácia na geração de poder. Controlar os estoques de um produto é importante, mas ainda mais importante é dispor de recursos financeiros para prolongar esse controle. Dispor de recursos de petróleo é uma arma, mas a eficácia dessa arma pode aumentar consideravelmente se se consegue organizar globalmente a oferta de petróleo no mercado internacional.

\section{Considerações finais: desdobramentos das reflexões}

Furtado, com sua análise sobre a "modernização", nos mostra que os desafios para a construção da nação brasileira são cada vez mais complexos, fato que o leva a trabalhar numa perspectiva cada vez mais interdisciplinar e com ênfase nas variáveis externas, dada a força que possuem na conformação das decisões que são tomadas no plano interno. Por isso que as saídas para a situação do subdesenvolvimento passam pelo repensar o desenvolvimento na periferia numa perspectiva de busca de soluções e ações de caráter conjunto entre esses países.

A partir das suas elaborações teóricas na década de 1970, Furtado continuaria refletindo em obras posteriores as alternativas para o Brasil diante dos desafios que iam surgindo para a nação brasileira: a crise econômica da década de 1980, como observamos em O Brasil Pós- "Milagre” (FURTADO, 1981) e os riscos da adesão ao neoliberalismo, como observamos em Brasil: A Construção Interrompida (FURTADO, 1992).

Podemos também afirmar, a partir do que foi analisado neste trabalho, que as aproximações do pensamento de Celso Furtado com a teoria da dependência, em especial na sua vertente marxista, demonstra a construção coletiva do conhecimento a partir do debate e da própria evolução dos acontecimentos, tal como a sociologia do conhecimento de Mannheim chama a atenção, provocando, nesse processo a criação de uma nova langue na parole, ou seja, nas expressões de Pocock, inovação no debate sobre o binômio desenvolvimentosubdesenvolvimento através das elaborações teóricas da CEPAL, de Furtado e da teoria da dependência, tal como podemos observar em expressões como deterioração dos termos de troca, centro, periferia, dependência, dentre outras.

\section{Referências}

BENDIX, R. Construção nacional e cidadania. São Paulo: Editora da USP, 1996. (1 ${ }^{\mathrm{a}}$ edição: 1964; $2^{\mathrm{a}}$ edição, com acréscimo do capítulo 8: 1977).
BICHIR, M. M. A problemática da dependência: um estudo sobre a vertente marxista da dependência. 2012. Dissertação (Mestrado em Ciência Política)Universidade Estadual de Campinas, Campinas, 2012.

BIELSCHOWSKY, R. Pensamento econômico brasileiro: o ciclo ideológico do desenvolvimentismo. Rio de Janeiro: Contraponto, 2000.

CARDOSO, F. H.; FALETTO, E. Dependência e desenvolvimento na América Latina. Rio de Janeiro: Zahar Editores, 1984. (1 $1^{\mathrm{a}}$ edição: 1970).

FURTADO, C. Características gerais da economia brasileira. Revista Brasileira de Economia, ano 4, n. 1, p. 7-36, 1950.

FURTADO, C. A programação do desenvolvimento econômico II. Revista do Conselho Nacional de Economia, v. 2, n. 19-20, p. 11-15, 1953.

FURTADO, C. A economia brasileira. Rio de Janeiro: Editora A Noite, 1954a.

FURTADO, C. A técnica do planejamento econômico. Revista de Ciências Econômicas da Ordem dos Economistas de São Paulo, ano XI, n. 70, p. 3-13, 1954 b.

FURTADO, C. Uma economia dependente. Rio de Janeiro: Ministério da Educação e Cultura, 1956a.

FURTADO, C. Setor privado e poupança. Economica Brasileira, v. II, n. 2, p. 100-102, 1956 b.

FURTADO, C. Fundamentos da programação econômica. Econômica Brasileira, v. IV, n. 1-2, p. 39-44, 1958.

FURTADO, C. Desenvolvimento e subdesenvolvimento. Rio de Janeiro: Fundo de Cultura, 1961.

FURTADO, C. A pré-revolução brasileira. Rio de Janeiro: Fundo de Cultura, 1962.

FURTADO, C. Dialética do desenvolvimento. Rio de Janeiro: Fundo de Cultura, 1964.

FURTADO, C. Subdesenvolvimento e estagnação na América Latina. Rio de Janeiro: Civilização Brasileira, 1966.

FURTADO, C. Um projeto para o Brasil. Rio de Janeiro: Saga, 1968a.

FURTADO, C. Brasil: da República oligárquica ao Estado militar. In: FURTADO, C. (Org.). Brasil: tempos modernos. Rio de Janeiro: Paz e Terra, 1968b. p. 1-23..

FURTADO, C. O mito do desenvolvimento econômico. Rio de Janeiro: Paz e Terra, 1974.

FURTADO, C. Prefácio a nova economia política. Rio de Janeiro: Paz e Terra, 1976.

FURTADO, C. Criatividade e dependência na civilização industrial. Rio de Janeiro: Paz e Terra, 1978.

FURTADO, C. O Brasil pós- “milagre”. Rio de Janeiro, Paz e Terra, 1981.

FURTADO, C. Análise do "modelo" brasileiro. Rio de Janeiro: Civilização Brasileira, 1982. (1 a edição: 1972).

FURTADO, C. Brasil: a construção interrompida. Rio de Janeiro: Paz e Terra, 1992.

FURTADO, C. Aventuras de um economista brasileiro. In: FURTADO, C. (Org.). Obra autobiográfica. São Paulo: Paz e Terra, 1997. v. 2.

FURTADO, C. Economia colonial no Brasil nos séculos XVI e XVII. São Paulo: HUCITEC; ABPHE, 2001. (Tese de Doutorado, 1948). 
FURTADO, C. Formação econômica do Brasil. São Paulo: Companhia das Letras, 2007. (1 $1^{\mathrm{a}}$ edição: 1959).

GEERTZ, C. The integrative revolution: primordial sentiments and civil politics in the new states. In: HUTCHINSON, J.; SMITH, A. D. (Orgs). Nationalism: critical concepts in political science. Londres: Routledge, 2000. (artigo publicado originalmente em 1963).

GIAMBIAGI, F.; VILlELA, A.; CASTRO, L. B.; HERMANN, J. (Orgs.). Economia brasileira contemporânea: 1945-2010. 2. ed. Rio de Janeiro: Elsevier, 2011.

KOHN, H. A era do nacionalismo. Rio de Janeiro: Fundo de Cultura, 1963.

MANNHEIM, K. Ideologia e utopia. Rio de Janeiro: Zahar Editores, 1972.

MANNHEIM, K. Sociologia da cultura. São Paulo: Perspectiva, Editora da USP, 1974.

MANTEGA, G. A economia politica brasileira. Petrópolis: Vozes; São Paulo: Polis, 1984.

MARINI, R. M. Dialética da dependência. Petrópolis: Vozes; Buenos Aires: CLACSO, 2000.

MATOSSIAN, M. Ideologies of delayed industrialization: some tensions and ambiguities. In: HUTCHINSON, J.; SMITH, A. D. (Orgs). Nationalism: critical concepts in political science. Londres: Routledge, 2000. (artigo publicado originalmente em 1958).
MELLO, J. M. C. O capitalismo tardio. São Paulo: Brasiliense, 1982.

MILLIKAN, M. F.; BLACKMER, D. L. M. (Orgs.). Nações em desenvolvimento: a sua evolução e a politica americana. Rio de Janeiro: Fundo de Cultura, 1963.

MYRDAL, G. Teoria econômica e regiões subdesenvolvidas. Rio de Janeiro: Saga, 1972. (1ª edição: 1956).

NURKSE, R. Problemas da formação de capital em países subdesenvolvidos. Rio de Janeiro: Civilização Brasileira, 1957.

POCOCK, J. Linguagens do ideário politico. São Paulo: Editora da USP, 2003.

PREBISCH, R. El desarrollo económico de la américa latina y algunos de sus principales problemas. In: CEPAL (Ed.). Estudio económico de la América Latina 1948. Santiago do Chile: CEPAL, 1949.

PREBISCH, R. Dinâmica do desenvolvimento latinoamericano. Rio de Janeiro: Fundo de Cultura, 1964.

ROSTOW, W. W. Etapas do desenvolvimento econômico: um manifesto não comunista. Rio de Janeiro: Zahar, 1964.

SANTOS, T. A teoria da dependência: balanço e perspectivas. Rio de Janeiro: Civilização Brasileira, 2000.

Recebido: 11 mar., 2015 Aceito: 09 jun., 2015 